SEÇÃO

RESENHAS 
Filho da floresta, água e madeira

vão na luz dos meus olhos,

e explicam este jeito meu de amar as estrelas e de carregar nos ombros a esperança.

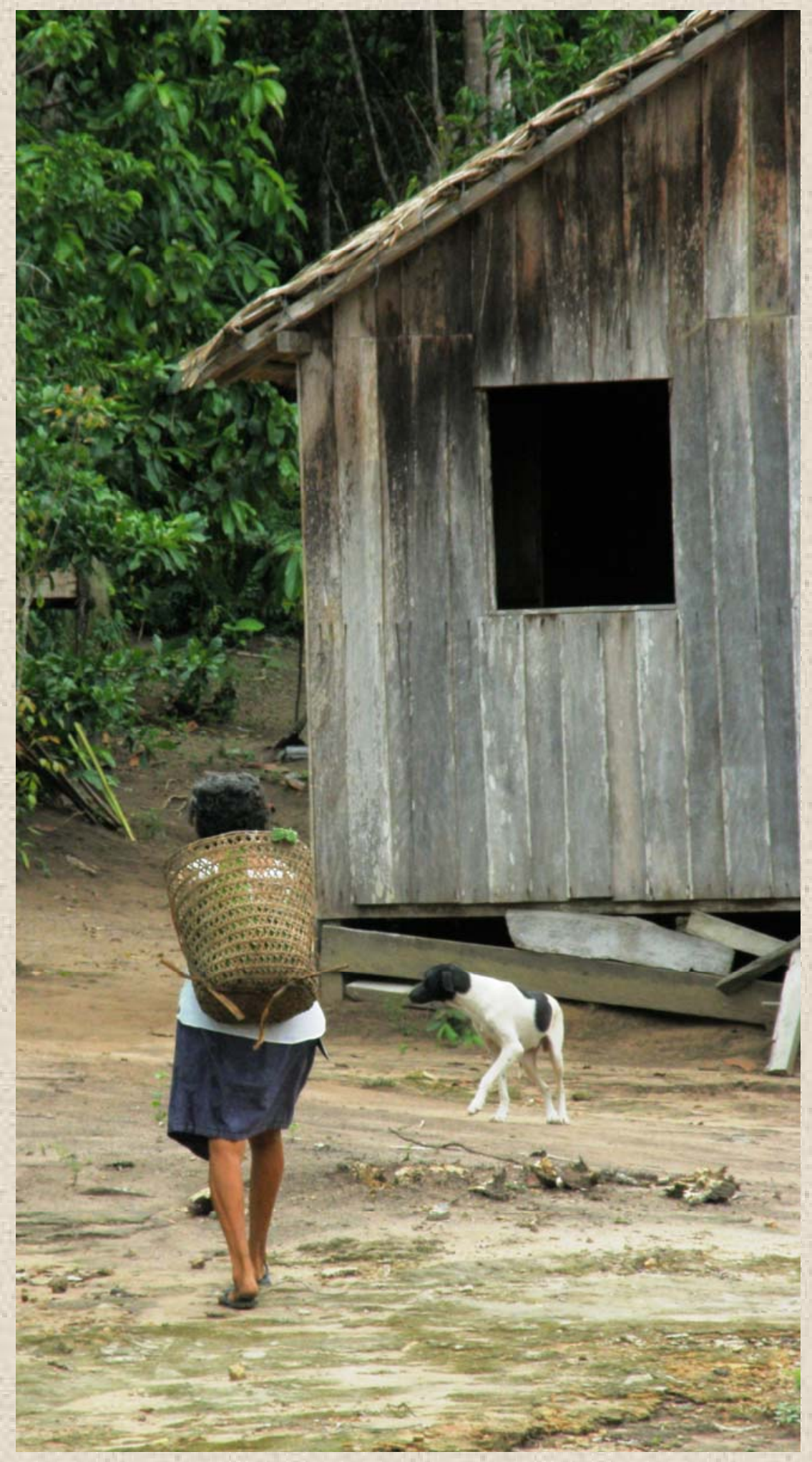

(Thiago de Mello: Filho da floresta, água e madeira) 


\section{A percepção da paisagem para a organização territorial do turismo}

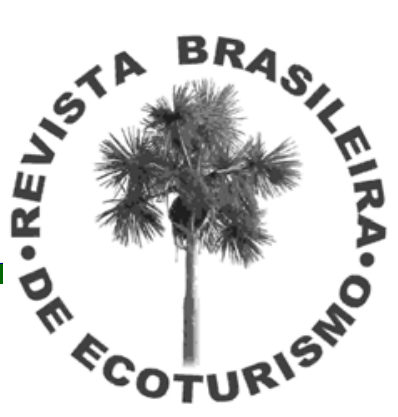

\section{Marcelo Teixeira Cesar de Oliveira}

Xavier, H. A percepção geográfica do turismo. São Paulo: Aleph, 2007.

Paisagens, quero-as comigo.

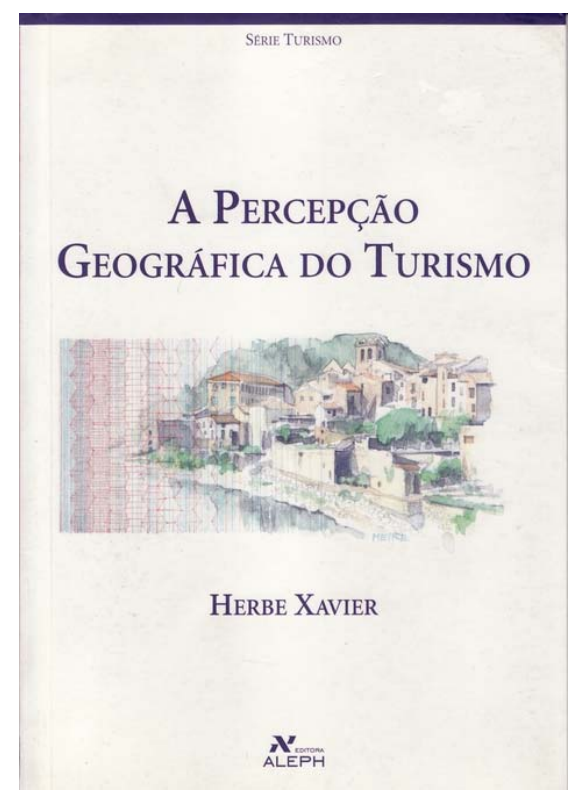

Paisagens, quero-as comigo. Paisagens, quadros que são... Ondular louro do trigo, Faróis de sóis que sigo, Céu mau, juncos, solidão...

Umas pela mão de Deus, Outras pelas mãos das fadas, Outras por acasos meus, Outras por lembranças dadas...

Paisagens... Recordações,

Porque até o que se vê Com primeiras impressões Algures foi o que é, No ciclo das sensações.

Paisagens... Enfim, o teor

Da que está aqui é a rua Onde ao sol bom do torpor Que na alma se me insinua Não vejo nada melhor.

(Fernando Pessoa)

O turismo é uma atividade crescente em todo mundo. As mudanças de hábitos do homem moderno, os processos de migração do campo para as cidades, o inchaço dos centros urbanos e a mudança de diversos paradigmas tem criado um interesse cada vez maior na atividade e no desdobramento de uma grande diversidade de roteiros, destinos e opções. Novos lugares têm sido procurados, alguns onde nunca existiu atividade turística, e a organização deste espaço passa a ser alimentada por outros interesses, outros vetores que alteram a configuração original dos lugares.

A percepção e a representação deste espaço geográfico alterado pelo turismo devem ser melhor estudadas tão rápido quanto o "boom" do turismo invade a transforma alguns desses lugares. O turista que chega a este novo lugar não tem a mesma percepção e relação afetiva que o autóctone e capta, percebe e se relaciona de forma diferente com a paisagem geográfica.

Neste contexto Herbe Xavier elaborou "A percepção Geográfica do Turismo" 
pela Editora Aleph em que destaca a importância dos fatores culturais e da percepção na elaboração da paisagem através de uma abordagem perceptiva para os estudos de turismo. Busca levar em consideração o sentimento das pessoas e seus laços afetivos com o meio ambiente e as suas atitudes em relação aos lugares como desafio a que se colocou fruto de vários anos de pesquisa e em sua atividade docente.

Herbe Xavier possui graduação em Geografia pela Universidade Federal de Minas Gerais (1969) , especialização em Geografia Regional pela Pontifícia Universidade Católica de Minas Gerais (1976), mestrado (1990) e doutorado (1996) em Geografia pela Universidade Estadual Paulista Júlio de Mesquita Filho. Atualmente é professor titular da Pontifícia Universidade Católica de Minas Gerais. É autor de diversos artigos sobre a sustentabilidade ecológica do turismo, a incorporação da dimensão do turismo no ensino da geografia e a observação da paisagem.

A obra está organizada em sete capítulos, sendo que os primeiros formam a sua base para fundamentação de seus argumentos finais onde trata o turismo como fenômeno geográfico, da percepção geográfica e, finalmente, a percepção geográfica da paisagem. Nos capítulos restantes considera os valores locais na organização territorial, a necessidade do envolvimento das comunidades receptoras e a meta em alcançar a sustentabilidade socioambiental para atividade turística de base local.

No primeiro capítulo, Herbe Xavier expõe o contexto da atividade turística no mundo moderno, os novos valores e as novas necessidades que foram criadas no século XX, a influência da tecnologia e a alteração dos hábitos de consumo. Cita autores que colocam a pós-modernidade dentro de uma nova ordem sócio- econômica, com o crescimento do setor de prestação de serviços e as novas organizações sociais pós industriais. Nesse mundo abre-se espaço para as atividades de recreação, lazer e turismo. Alguns bens naturais passam a agregar outros valores e a natureza como matéria neutra sofre a ação das atividades humanas que valorizam ou desvalorizam seus recursos e impõe possíveis impactos. Coloca a cultura humana como determinante na consideração dos benefícios e contradições que o turismo pode trazer. Conclui ao demonstrar a importância da contribuição da geografia como ciência que trata as relações espaciais e pode considerar os aspectos sociais, culturais e ecológicos para oferecer subsídios para o tratamento das três sustentabilidades do turismo: a ecológica, a social e a econômica.

No capítulo seguinte, o autor desenvolve sua argumentação com relação à percepção geográfica e a atividade turística e seus padrões de distribuição espacial, tanto nos lugares da oferta como da demanda. Desenvolve as bases para o entendimento da apreensão e construção de conceitos de paisagem percebida a partir dos sentidos e da interpretação. Baseia-se em autores como Lynch ${ }^{1}$, Piaget $^{2}$, Gibson $^{3}$ e Tuan $^{4}$ e justifica a necessidade deste estudo em turismo pela necessidade de abordar a conduta do homem diante do espaço geográfico, prestando melhores esclarecimentos com respeito a sua relação com a natureza e os grupos humanos diante da atividade turística. Com a percepção cognitiva do espaço, que sustenta todas as categorias de atrativos turísticos, a compreensão torna-se mais abrangente a partir da abordagem 
das percepções. Defende que as atitudes adotadas pelas pessoas no turismo processam-se através dessa percepção e ainda, que espelham seus interesses e valores a ele atribuídos e que refletem a sua visão de mundo. Ao considerar a paisagem composta por elementos naturais e construídos, visíveis e não visíveis torna-a matériaprima do turismo. É nela que as pessoas se deslocam, agregam valores sociais, ambientais, econômicos, afetivos e simbólicos e alteram seus componentes.

Herbe Xavier, no capitulo três, segue com o argumento de que a paisagem no turismo deve ser interpretada e com isso agrega valor ao que é percebido. Na paisagem a vida do homem passa, transcorrem sua ações e assim pode-se entender meIhor através dela a organização do espaço. Destaca a importância do trabalho de Milton Santos ${ }^{5}$ e seu tratamento dialético da paisagem ao considerar inseridos nesta os objetos naturais e os sociais implantados pelo homem. A paisagem definida pela visão e interpretada pela mente tem nessa a acumulação das atividades de várias gerações, renovada, alterada, suprimida ou mantida e em constante modificação, ainda assim, apenas como aparência. Outra abordagem do capítulo com relação à percepção geográfica da paisagem volta à questão da paisagem percebida, não para sua fundamentação, mas de sua aplicação ao estudo do turismo. A paisagem que se constitui como habitat deve ser capaz de suportar a subsistência do homem, a sua natureza, a moral e a estética. Neste contexto acrescenta os axiomas de Peirce F. Lewis ${ }^{6}$, que são usados para interpretar cenas americanas. Prossegue na argumentação com outros autores onde destaca que aquilo que percebemos trata-se de um trabalho contínuo dos grupos humanos em busca de um relacionamento viável com a natureza. Neste capítulo, discordo do autor em separar em dois capítulos a questão da percepção da paisagem e da questão da percepção geográfica da paisagem, já que acaba não fazendo uma distinção clara do que pretendia neste capítulo. Poderia ter trabalhado os dois capítulos como um só.

Ao citar outros autores, Herbe Xavier desenvolve no capítulo quatro as questões ligadas à organização territorial do turismo apoiado nos valores locais. Coloca que o turismo de fato nasceu com a indústria ao surgir como turismo de elite na revolução industrial, precedido pelo de massa e depois o da modernidade e dos recursos tecnológicos. Com isso também se deu início a um enorme processo de segmentação, resultado da ampliação das opções de destinos, de acessos, de liberdade de visões de mundo e das oportunidades das viagens de negócios. Quando resolve tecer alguns comentários sobre a origem do Ecoturismo no mundo e no Brasil eu acabo por discordar do autor por atuar na área desde o seu surgimento no país. Ele não embasa sua argumentação histórica em nenhum autor e defende que o movimento de turismo alternativo foi iniciado na Europa e se espalhou pelo planeta. Inicialmente as primeiras entidades ligadas ao Ecoturismo como prática alternativa teriam surgido nos Estados Unidos da América. E cabe aqui aproveitar que nunca gostei do termo Ecoturismo, pois remete a indústria do turismo de massa existente anteriormente como responsável pela origem da atividade no país. O trade tradicional não teve responsabilidade nenhuma no surgimento e na constituição inicial da atividade no Brasil, ela surgiu de 
um segmento heterogêneo de empreendedores não ligados à indústria do turismo, mas sim de pessoas que tornaram sua prática de trilhas como "hobbie" de "retorno" a natureza e tornando-a consequentemente atividade profissional.

$\mathrm{O}$ autor segue e defende que a mudança dos paradigmas sobre o que a humanidade considera patrimônio natural e cultural possa de forma importante abrir ótimas perspectivas para reforçar o desenvolvimento de turismo com base nos valores locais. Completa mais adiante onde considera que o bem turístico não desaparece ao ser consumido ao contrário de outras mercadorias. Mas também, pontua que o mesmo, apesar disso, pode ser perdido como consequência da degradação. Por fim, destaca Boullón ${ }^{7}$ e seu trabalho com a organização regional do turismo.

Conclui sua obra ao colocar a dimensão social e o envolvimento da comunidade no turismo para partir em busca da sustentabilidade no turismo destacando a importância fundamental dos fatores cognitivos e afetivos na construção do espaço do turismo e na incorporação da dimensão social como condição fundamental. Apresenta autores que defendem que na lógica do turismo ainda prevalece a consideração dos valores dos viajantes e dos promotores de viagens em detrimento de conhecer os interesses das comunidades locais. Uma das principais considerações do capítulo se relaciona ao forte impacto do turismo sobre as comunidades tradicionais quando seus "bens de uso" tornam-se do dia para a noite em "bens de consumo", e passa a valor de mercadoria, fator importante que pode corromper valores sociais até então vigentes. Discute a importância do envolvimento da comunidade no processo para a implantação do turismo de base local. Afirma ainda, que é preciso considerar as experiências, os valores e os interesses e as expectativas dos grupos sociais das comunidades receptoras. Como caminhos para a sustentabilidade e a inclusão social na atividade turística, aponta para a importância da Educação Ambiental e o desenvolvimento de pesquisas para levar a comunidade a identificar e valorizar as potencialidades do lugar. Criar formas de cooperativismo, associativismo e desenvolver estudos interdisciplinares em busca do turismo de inclusão na condução do sentido do pertencimento também são destacados por Herbe.

Concluo também que deve hoje existir um incentivo para o grande desenvolvimento urgente do empreendedorismo local com capacitação e orientação com acompanhamento e análise constante de uma equipe técnica devidamente preparada. Para finalizar, na análise da sustentabilidade coloca a necessidade de envolvimento de profissionais de diferentes formações e suas contribuições e a incorporação de estudos sobre meio ambiente em busca da sustentabilidade do turismo e pode incluir os aspectos ecológicos, social, político, cultural e econômicos. Sempre irá restar, numa obra dessas, outras questões para serem debatidas, sendo esta um bom começo para a discussão deste tema atual. Quem deve decidir qual paisagem deve ser "implantada" em turismo? Quais os interesses do trade turístico, dos planificadores, dos técnicos? Apesar de algumas observações e considerações para ampliação de futuros debates, a obra deve ser lida e consultada por aqueles que desejam estudar a temática sob a ótica da percepção geográfica da paisagem no turismo. 


\section{Notas}

${ }^{1}$ Kevin Andrew Lynch, urbanista norte-americano graduado no Instituto de Tecnologia de Massachusetts (ITM) autor de "The Image of the city (1960)" onde apresentou sua pesquisa sobre como os indivíduos observam, percebem e transitam no espaço urbano.

${ }^{2}$ Jean Piaget, biólogo e filósofo suiço graduado na Universidade de Neuchâtel que se dedicou à Psicologia, Epistemologia e Educação e desenvolveu a Teoria Piagetiana do Desenvolvimento Perceptivo; autor de "Psicologia da Inteligência" (1961).

${ }^{3}$ James Jerome Gibson, psicólogo norte-americano graduado em Psicologia pela Universidade de Princeton autor de "Perception of the Visual World" (1950) onde expõe a Teoria da percepção dos sentidos.

${ }^{4}$ Yi-Fu Tuan, geógrafo chinês autor de "Topofilia, Um estudo da percepção, atitudes e valores do meio ambiente." (1980) onde apresenta um estudo de percepção do meio material pelos seres humanos considerando laços afetivos, as atitudes e os valores.

${ }^{5}$ Milton Santos, geógrafo brasileiro, foi professor da Universidade de São Paulo, autor de "Pensando o Espaço do Homem" (1982) entre tantos outros artigos e livros.

${ }^{6}$ Peirce F. Lewis, Geógrafo americano, professor da Universidade do Estado da Pensilvânia, autor de "Axioms for reading the American landscape" (1979) onde mostra sua pesquisa sobre a paisagem e cultura americana.

${ }^{7}$ Roberto C. Boullón autor de "Planejamento do Espaço Turístico", (2002).

Marcelo Teixeira Cesar de Oliveira: Ipá Ti-uá Vivência Ambiental; e Centro Universitário São Camilo

Email: marcelotco@usp.br

Link para o currículo Lattes: http://lattes.cnpq.br/9753845132226588

Data de submissão: 05 de janeiro de 2009

Data de aceite: 05 de janeiro de 2009 